\title{
The Minimalist Theory of Truth: Challenges and Concerns
}

\begin{abstract}
Minimalism is currently the received deflationary theory of truth. On minimalism, truth is a trivial concept and a deflated property of truth bearers. In this paper, I first situate minimalism within current deflationary debate about truth by contrasting it with its main alternative-the redundancy theory of truth (according to which truth is trivial concept but not a property). I then outline and appraise two of the primary challenges facing minimalism. Finally, based on this discussion, I draw some conclusions concerning the soundness and stability of minimalism.
\end{abstract}

\section{Introduction}

The fundamental thesis of deflationism is that truth is a trivial and transparent concept. If the truth predicate has any content, the deflationist claims, it is exhausted by its involvement in some version of truth-schema $[\mathrm{p}]$ is true iff $\mathrm{p}$ (where ' $[\mathrm{p}]$ ' denotes an utterance, sentence or proposition and 'p' denotes '[p]'s object level equivalent). For example, sentential deflationism holds that the content of the truth predicate is exhausted by its involvement in the disquotational schema 'p' is true iff $p$ (where ' $p$ ' is a sentence and 'p' is its object level equivalent). On this doctrine, truth is defined in English by an infinite list of axioms

$\left(\mathrm{T}_{1}\right)$ 'snow is white' is true iff snow is white,

$\left(\mathrm{T}_{2}\right)$ 'grass is green' is true iff grass is green,

and correspondingly for all declarative sentences in the language.

Defined by the triviality thesis, deflationism divides into two main camps according to ontological commitment. On strong deflationism, truth is not only a trivial concept but a 
redundant one (see Ramsey, 'Facts and Propositions'; Ayer, Language, Truth, and Logic; and Strawson, 'Truth'). On this view, the truth predicate doesn't designate a property, i.e., there is no property of truth. On weak deflationism, while the concept of truth is trivial, it is not redundant (cf. Horwich, Truth, ‘A Defense of Minimalism'; Sosa, 'The Truth of Modest Realism'; Soames, 'The Truth About Deflationism', Understanding Truth; Field, 'Deflationist Views of Meaning and Content'; Gupta, 'Minimalism' and 'A Critique of Deflationism'). Since 'is true', it is claimed, is logically indispensible, it must designate a property. It is just that the property of truth, on this view, is deflated in some sense, e.g., it is not substantial, theoretically important, interesting, explanatory, a natural kind or anything in this general vicinity.

In this paper, the focus will be on the received variant of deflationism, weak deflationism or what Horwich calls 'minimalism'. I first situate minimalism within current deflationary debate about truth by pinpointing the primary reasons for its supremacy among deflationists. I then outline and appraise two pivotal challenges facing minimalism: its formulation and explanatory adequacy. Finally, based on this discussion, I draw some fundamental lessons for the soundness and stability of the minimalist conception of truth.

\section{Motivations for Minimalism}

At things currently stand, minimalism is the dominant deflationary theory of truth. It is now virtually universally acknowledged that the truth predicate, if nothing else, is a denominalizor or device of semantic ascent that restores objective reference for certain kinds of expressions by permitting one to refer to the objects of one's attitude in a determinate way. In this respect, the truth predicate unquestionably increases the expressive resources of the language: it enables us to 
formulate certain kinds of statements it would otherwise be impossible to formulate, i.e., universal generalizations (e.g., 'everything Plato claimed is true') and so-called blind ascriptions (e.g., 'whatever Plato claimed at his first university lecture is true').

In view of the logical/expressive indispensability of the truth predicate, the strong deflationist must be wrong that the truth predicate is redundant, eliminable or replaceable by some other logical mechanism. The inescapable inference is that 'is true' functions semantically as a predicate-that it designates a property (i.e., a deflated property).

Numerous commentators including Quine (Philosophy of Logic 11-13), Grover et al. ('A Prosentential Theory of Truth' 81-6), Gupta ('Minimalism' 366-8), Soames ('The Truth About Deflationism' 247-9), and Horwich (Truth 3) have effectively demolished the redundancy thesis underlying the strong deflationary theory of truth (hereafter the 'redundancy' theory). ${ }^{1}$ Since ' $[\mathrm{p}]$ ' and ' $[\mathrm{p}]$ is true' are not synonymous or equivalent in terms of cognitive content, it is urged, the truth predicate is not redundant or eliminable. Since expressions containing the truth predicate cannot be rewritten truth-independently, the reasoning runs, the truth predicate is logically indispensable.

Consider the universal generalization 'everything Plato claimed is true'. It might be reconstructed as 'for all $\mathrm{p}$, if Plato claimed that $\mathrm{p}$, then $\mathrm{p}$ ' or, more specifically, as a long series of clauses, one for each potential claim made by Plato: 'If Plato claimed there is a universal form of happiness, there is a universal form of happiness', 'If Plato claimed children should be educated in mathematics and music, children should be educated in mathematics and music', and so on. The problem with this truth-independent reconstruction is that it is possible to have different propositional attitudes towards it and the generalization it reconstructs, implying their cognitive inequivalence. As Gupta ('Minimalism' 363-5) and Soames (Understanding Truth 
233-8) have shown, it is possible to believe 'everything Plato claimed is true' without believing the conjunction of all its instances. While one might believe 'everything Plato claimed is true' on general grounds (e.g., based on Plato's character or intellect), one might reject a specific claim made by Plato when its content is revealed (e.g., the claim that all children in the ideal republic should live separately from their biological parents).

Next, consider the de facto reconstruction of the blind ascription 'whatever Plato claimed at his first university lecture is true'. Its truth-independent replacement- ' for all $\mathrm{p}$, if Plato claimed $\mathrm{p}$ in his first university lecture, then p'-suffers from the same basic defect as the reconstructed universal generalization. The blind ascription and its truth-independent reconstruction are indisputably cognitively inequivalent since it is possible to have different propositional attitudes towards them (for the same reasons this is possible in the case of the universal generalization).

The important point to bear in mind is that a truth predicated universal generalization is not cognitively equivalent to the totality of its instances, and a truth predicated blind ascription is not cognitively equivalent to a statement (or set of statements) endorsing the actual claim(s) the truth predicated ascription is blindly endorsing. Consequently, the redundancy theorist cannot rewrite the truth predicated statements using counterfactual schemata of the kind proposed.

Perhaps, though, the redundancy thesis might be defended via a different reconstruction strategy. There appear to be only two options available in this case: rewriting the truth predicated statements using (1) ordinary objectual quantification or (2) substitutional quantification.

Consider the first strategy. In this case, the generalization 'everything Plato claimed is true' is rewritten as 'For all $\mathrm{x}$, if Plato claimed $\mathrm{x}$, then $\mathrm{x}$ ' via the formula ( $\forall \mathrm{x}$ ) (If Plato claimed that $\mathrm{x}$ $\rightarrow \mathrm{x})$. Unfortunately, this truth-independent reconstruction is manifestly incoherent. It is generally acknowledged (Black, 'The Semantic Definition of Truth' 51-2; Alston, A Realist 
Conception of Truth 28; Kirkham, Theories of Truth 335-6) to be ill-formed in two distinct ways: (a) the second occurrence of ' $x$ ' would be in an opaque context beyond the reach of normal quantification and (b) a variable ranging over objects, specifically, the third occurrence of ' $x$ ', appears in sentential positions. The same problem applies mutatis mutandis to the objectually quantified reconstruction of the aforementioned truth predicated blind ascription.

Next, consider the substitutional quantification strategy for truth-independent reconstruction. The reconstruction of the generalization 'everything Plato claimed is true' in this case would be the same formula as the objectually quantified reconstruction, 'For all $\mathrm{x}$, if Plato claimed $\mathrm{x}$, then x', except the variables would be interpreted substitutionally instead of objectually-as prosentences instead of as noun phrases referring to objects. Blind ascriptions would be reconstructed in an analogous manner.

One concern with the substitutional quantification strategy is that it furnishes us with a truthindependent reconstruction only by exploiting a special set of syntactic and semantic rules. The substitutional quantifier would doubtless be a cumbersome addition to our language since it exploits a new-fangled logical apparatus. The main objection to this strategy, though, concerns the explanation of substitutional quantification: substitutional quantification scarcely seems intelligible in truth-independent terms (cf. Horwich, Truth 4-5, 25-6; David, Correspondence and Disquotation 88-93; McGrath, 'Weak Deflationism' 75-7; Kovach, 'Deflationism and the Derivation Game 575-76). For example, in the substitutionally quantified formula 'For all x, if Plato claimed that $x \rightarrow x^{\prime}$, the variable $x$ is associated not with a range of objects but with a substitution class of expressions. In interpreting this formula, the most intuitive reading is that any result of substituting an English declarative sentence for $\mathrm{x}$ in 'For all $\mathrm{x}$, if Plato claimed that $\mathrm{x} \rightarrow \mathrm{x}^{\prime}$ is true, correct or valid. But rather than eliminate it, truth or some close cognate is 
featured centrally in this explanation. While the strategy cannot dismissed out of hand, given its significant shortcomings, substitutional quantification, like objectual quantification, looks unpromising as a mode of truth-independent reconstruction.

While the supremacy of minimalism among deflationists stems from the implausibility of redundancy theses, there is a separate question of the motivation for eschewing inflationism. Some of the more well-known reasons for rejecting inflationism in favor of deflationism include adherence to the formal simplicity (Horwich, Truth Ch. 2 \& 3), ontological purity (Horwich (Truth Ch. 4 \& 7) and classical interpretation of truth. In respecting these commitments, minimalism might be viewed as privileged over inflationary theories of truth such as correspondence and epistemic theories that deny truth is a trivial concept and deflated property. ${ }^{2}$

\section{Formulation of Minimalism}

In its most common formulation, the minimalist theory of truth (hereafter 'MT') consists of the infinite set of non-paradoxical propositions instantiating the equivalence schema (Horwich, Truth 6-7, 17-20 and 'A Defense of Minimalism' 150-51): '

(E) The proposition that $p$ is true iff $p$.

This would seem to be the only acceptable formulation of minimalism. The problem is that the other two main strategies for formulating minimalism, objectual quantification and substitutional quantification, look fundamentally defective. 
First, minimalism might be formulated as the objectually quantified first order generalization ( $\forall \mathrm{x})$ (if $\mathrm{x}$ is a proposition of the form $\mathrm{p} \leftrightarrow \mathrm{p}$ then $\mathrm{x}$ is true), which reads 'For all $\mathrm{x}$, if $\mathrm{x}$ is a proposition of the form [ $p$ if and only if $p$ ] then $x$ is true' (cf. Sosa, 'The Truth of Modest Realism' 177-95; McGrath, 'Weak Deflationism' 73-7). The main concern with this formulation of minimalism is analogous to the concern identified (in $\S 2$ ) with objectually quantified truthindependent generalizations and blind ascriptions. First order generalizations such as 'For all p, the proposition that $\mathrm{p}$ is true iff p', when interpreted objectually, are incoherent or ill formed since the two occurrences of the variable ' $p$ ' refer to different kinds of entities.

Minimalism, it has been proposed, might be formulated as another kind of objectually quantified first order generalization: 'For all propositions $\mathrm{p}, \mathrm{p}$ is necessarily equivalent to the proposition with respect to it that it is true' (McGrath, 'Weak Deflationism' 76). But this approach preserves coherence at the cost of explanatory value. Since necessity and equivalence are typically thought best explained in terms of truth, there seem compelling grounds prohibiting them from being put to use in formulating minimalism (cf. David, Correspondence and Disquotation 88-93; Kovach, 'Deflationism and the Derivation Game' 576-7). At the very least, until these concepts are shown to be explicable in truth-independent terms, this objectually quantified formulation of minimalism must be deemed intolerably circular.

On the other hand, minimalism might be formulated as the substitutionally quantified first order generalization ( $\mathrm{p}$ )(the proposition that $\mathrm{p}$ is true $\leftrightarrow \mathrm{p}$ ), where the universal quantifier is interpreted substitutionally rather than objectually, as ranging over classes of expressions (or names of objects) instead of objects (e.g., Williams, 'What is Truth?' Ch. 3). The formula reads 'For each sentence in the language, if we substitute the sentence for the ' $p$ ' in 'the proposition that $\mathrm{p}$ is true $\leftrightarrow$ p', then we produce a true sentence'. 
This formulation of minimalism suffers two flaws, the second more vexing than the first. (1) It seems intolerably circular in the same way as are substitutionally quantified reconstructions of truth predicated universal generalizations and blind ascriptions. One is at pains to explain substitutional quantification without employing the concept of truth. (2) In the formula (p)(the proposition that $\mathrm{p}$ is true $\leftrightarrow \mathrm{p}$ ), there are inherent limitations on the substitution class associated with the variable 'p'. Since 'p' represents an English sentence, its substitution class must itself be a set of English sentences. But English does not have the resources to express every proposition that is a candidate to instantiate the equivalence schema.

In short, while the objections to finite formulations of minimalism are less than definitive, they bolster the appeal of Horwich's infinitistic formulation-MT. And while MT (the infinite, irreducible set of T-propositions) is not a uniform theory of truth, this should not be of great concern. After all, one of the fundamental theses of minimalism is that truth is not an ordinary sort of property, “... a characteristic whose underlying nature will account for its relations to other ingredients of reality" (Horwich, Truth 2). And as Horwich points out right at the beginning of Truth, this implies that "... unlike most other predicates, 'is true' should not be expected to participate in some deep theory of that to which it refers-a theory that articulates general conditions for its application" (2) (my emphasis). On this plausible view of matters, it is no revelation that the only seemingly acceptable 'formulation' of minimalism, MT, doesn't really look like a theory of truth.

\section{Minimalism and Explanatory Adequacy}

Besides its formulation, there is an important question concerning the explanatory merits of minimalism. A touchstone for any proposed theory of truth is its explanatory value, its ability to 
explain uncontroversial facts or generalizations about truth, ${ }^{4}$ i.e., to face up to the so-called 'generalization problem' (cf. Armour-Garb, 'Minimalism, The Generalization Problem and The Liar' 491). For the minimalist, the challenge will be to account for the wide variety of generalizations about truth armed only with what Horwich calls the minimalist conception of truth, i.e., MT plus theories about the axioms of MT to the effect that they are epistemologically and explanatorily fundamental.

It is commonly maintained, though, that minimalism fails this challenge. Minimalism is widely considered explanatorily deficient since it does not contain or imply generalizations about truth, including generalizations relating truth to principles of action (e.g., all true beliefs tend to engender successful action), to modal principles (e.g., all true statements are possibly true), to principles of logic and other principles.

For example, consider truth's relationship to the logical principle of closure:

(C) For any propositions $\mathrm{p}$ and $\mathrm{q}$, if $\mathrm{p}$ is true and $\mathrm{p}$ implies $\mathrm{q}$ then $\mathrm{q}$ is true.

Minimalism does not contain this logical principle since it consists entirely of individual Tpropositions of the form $<\mathrm{p}>$ iff $\mathrm{p}$. While minimalism gives us all the instances of $(\mathrm{C})$, it does not give us (C) itself. Minimalism does not imply (C) since (C) is not cognitively equivalent to the totality of all its instances (Soames, Understanding Truth 247-9; Gupta, 'Minimalism' 364). ${ }^{5}$ A universal generalization is not cognitively equivalent to all its instances for reasons already discussed, i.e., since it is possible to have different propositional attitudes towards a generalization and the set of all its instances. 
Unsurprisingly, the minimalist has a reply to this kind of objection. Despite appearances, it is argued, minimalism needn't contain or imply any fact about truth since, crucially, the various facts about truth do not concern truth per se (Horwich, Truth 47-9). The implication, the reasoning runs, is minimalism needn't explain the facts about truth itself; it need only explain them in conjunction with 'uncontroversial' external premises.

While it cannot be dismissed outright, it is highly contentious that truth does not have an explanatory role in the traditional sense. The infirmity of this view follows from the failings of its attendant explanatory stratagem: minimalism seems unable to explain facts or generalizations about truth without employing external premises far from uncontroversial, and seemingly off limits to deflationists about truth (cf. Gupta, 'Minimalism' 66; Kovach 'Deflationism and the Derivation Game’ 577-9).

Consider the application of this point to the logical principle of closure (C). The default minimalist strategy is to explain (C) on the basis of MT (the infinite set of T-propositions) in conjunction with certain other 'unproblematic' assumptions derived from logic. Horwich, for his part, claims to be able to explain (C) by conjoining MT with the logical principle of entailment (Truth 22-4, 'A Defense of Minimalism’ 156-7): ${ }^{6}$

(E) All propositions of the form $((p \&(p \rightarrow q)) \rightarrow q)$ come out as something like valid or correct.

One problem with this strategy concerns Horwich's use of (E): Horwich cannot help himself to this principle if it is best explained in terms of truth. As it happens, though, the received explanation of $(E)$ is an alethic one: all propositions of the form $((p \&(p \rightarrow q)) \rightarrow q)$ are 
propositions that emerge as true. Needless to say, unless there is some indication of how (E) might be explained in truth-independent terms, the minimalist cannot use it as a premise to explain $(\mathrm{C})$.

If we have things right, (E) cannot be formulated as the objectually or substitutionally quantified generalization 'for every sentence $\mathrm{p}$ and $\mathrm{q}$ if $\mathrm{p}$ entails $\mathrm{q}$, then if $\mathrm{p}$, then $\mathrm{q}$ ' for reasons canvassed in $\S 3$. Formulating (E) as an objectually quantified generalization produces a formula that is either incoherent or relies on a problematic truth-independent notion of necessity and/or equivalence. Formulating (E) as a substitutionally quantified generalization produces a formula with unduly restricted application that seems intolerably circular.

The other strategy the minimalist might employ is to explain (E) via an infinitary schema. In this case, the principle will be formulated as an infinite list of individual axioms:

$\left(\mathrm{E}_{1}\right)$ if "Jane lives in Toronto" entails "Jane lives in Canada" then if "Jane lives in Toronto" is true "Jane lives in Canada" is true,

$\left(\mathrm{E}_{2}\right) \quad$ if "Jane lives in Denver" entails "Jane lives in the United States" then if "Jane lives in Denver" is true "Jane lives in the United States" is true,

and correspondingly for each declarative sentence of the language. But for reasons that should now be apparent this is not a satisfactory formulation of (E). The problem is that while the infinitistic strategy gives us all the instances of (E), it does not give us (E) itself. Since a universal generalization is not cognitively equivalent to the totality of its instances, the infinitistic formulation neither contains nor implies the universal generalization expressed by (E). 
Horwich seems to appreciate the gravity of this challenge. In his most recent discussion of the generalization problem, Horwich attempts to alleviate these kinds of concerns via a nifty gambit. He claims to be able to derive (C) by conjoining minimalism with (E) and an extra explanatory premise concerning our brute dispositions to accept generalizations based on our acceptance of all their instances:

(D) Whenever someone can establish, for any $F$, that it is $G$, and recognizes that he can do this, then he will conclude that every $F$ is $G$ ('A Defense of Minimalism' 157) (Horwich's emphasis). For Horwich, assuming we are inclined to accept the axioms of MT, we can establish, for instance, that for any given conjunction $F$, that it is true only if its conjuncts are $G$, and as long as our ability to do so proceeds in this way, we can recognize we can do so ('A Defense of Minimalism' note 20). Granting (D), it follows that we will be predisposed to conclude that every conjunction is true if and only if its conjuncts are true (cf. Armour-Garb, 'Minimalism, The Generalization Problem and The Liar' 495-6). The same account, according to Horwich, can be given mutatis mutandis for any generalization about truth. ${ }^{8}$

I think this kind of strategy holds little promise. Notoriously, there are inexorable difficulties plaguing dispositional semantic analyses, analyses employing dispositions as reductive explanans for semantic notions. The main concern with Horwich's dispositionalist proposal is that it is not clear exactly what sets of dispositions are. Evidently, sets of dispositions (or patterns of sets of dispositions) are not natural kinds since dispositions ipso facto do not stand in explanatory or structural relations to one another. Indeed, it seems the question of what structural relations sets of dispositions bear to one another is really a meta-level question; if Collins is correct ('On the Proposed Exhaustion of Truth' 672-3), it can only be addressed at the level of theories of semantic competence-theories concerning the preconditions for learning and 
understanding the meanings of expressions. But in this case the appeal to dispositions would be superfluous since the theory of semantic competence would be doing all the explanatory work.

In spite of this, given the obscurity of the relevant issues, charitability might be in order in this case. The crucial point is even granting there is a truth-independent formulation of (E) and other required principles doesn't appear to rescue minimalism's explanatory prospects. Permitting the minimalist to invoke (E) and numerous other external principles in explaining facts about truth effectively weakens the 'adequacy thesis'. In particular, it is mysterious in this case what role the minimalist conception of truth is playing in explaining the facts at issue. Insofar as the principles of minimalism—-the T-propositions—are axioms of any acceptable theory of (propositional) truth, the 'unproblematic' external principles such as (E) seem to be doing all the explanatory work. Since (E), in this case, is consistent with and follows from any proposed theory of (propositional) truth, minimalism's explanation of $(\mathrm{C})$ is manifestly bankrupt. As a matter of course, any theory of truth, indeed any theory, can explain the 'facts about truth' in this manner, implying minimalism collapses into an absurdly trivial theory of truth with no axioms whatsoever, what Gupta calls the 'null theory of truth' ('Minimalism' 364).

There is a related, potentially equally serious problem concerning the explanatory value of minimalism. In explaining the so-called facts about truth in the proposed manner, minimalism must necessarily exploit a wide range of external principles/concepts/axioms/etc. Since there is no reason to think any such principle is explicable in terms of or reducible to a smaller set of more fundamental ones, there is no upper limit on the amount of principles that would need to be stipulated to sustain the 'adequacy thesis'. From this perspective, it is less than compelling that one of the professed aims of minimalism is realized-the deliverance of a simple or pure theory of truth. 
Naturally, there are manifold ways to evaluate the simplicity of a theory. On ontological grounds, minimalism might be deemed a simple theory since it entails the purity of truth, i.e., that truth is a property with 'no underlying connections to other ingredients of reality'. But there is a broader, more illuminating perspective from which minimalism seems to falls short on the simplicity metric. From what has been called an 'ideological' perspective (Gupta, 'Minimalism' 365-6), minimalism seems to be a maximally complex theory (cf. also O'Leary-Hawthorne and Oppy, ‘Minimalism and Truth' 179 \& 193; David, Correspondence and Disquotation 126-9). First, minimalism is irreducible, i.e., it requires a separate biconditional for each proposition. Second, for this reason, external principles will be required to explain the facts about truth, and there is no real way of knowing how many will be needed. It turns out, then, minimalism ultimately must contain all concepts and subsume the ideology of all theories. The upshot, if Gupta is right, is that even if minimalism were explanatorily adequate, “... it would be natural to be dissatisfied with it and to seek a simpler theory, a theory that explains the phenomena in a more economical fashion” ('Minimalism' 365).

While minimalism is formulatable, it seems to founder on the criterion of explanatory adequacy. Explaining the facts about truth requires the minimalist to exploit external principles that are far from uncontroversial, principles seemingly inexplicable in truth-independent terms. This verdict is buttressed by the recognition that permitting the use of these principles effectively weakens the adequacy thesis and correspondingly reduces minimalism to an absurdly trivial theory of truth. The unsoundness of minimalism seems to stem, on the flip side, from the insight that even granting minimalism's explanatory completeness, a strong case can be made that minimalism is, contra Horwich, a strikingly complex theory. 


\section{Conclusion: Minimalism and the Instability Concern}

If we are correct, minimalism isn't formulatable in finite terms. The only viable formulation of minimalism is MT: the infinite set of non-paradoxical instantiations of the equivalence schema. But since minimalism denies truth has an underlying nature the minimalist is scarcely required to formulate her theory of truth in a uniform manner.

On the other hand, there are serious questions about the explanatory merits of minimalism. The previous section's discussion suggests minimalism is explanatorily inadequate. The problem is minimalism is unable to explain putative uncontroversial facts about truth, either via infinitary schemas or finite formulas.

The putative explanatory deficiencies of minimalism seem to portend its instability. Minimalism's inability to explain uncontroversial facts about truth, it can be argued, imply its view of truth is fundamentally equivocal, i.e., that it threatens to collapse into either that of strong deflationism or some form of inflationism.

Among others, Boghossian ('The Status of Content'), Wright (Truth and Objectivity, 'Response to Commentators'), and O'Leary-Hawthorne \& Oppy ('Minimalism and Truth' 184) have developed variants of this basic kind of instability objection (although O'Leary-Hawthorne and Oppy suspend judgment on it). On this view of matters, there is no middle road when it comes to the ontological character of truth: either truth is a property in which case 'is true' is amenable to explicit analysis or truth is not a property in which case 'is true' is not amenable to explicit analysis. The attempt to draw a line between a minimal and non-minimal property of truth, it is claimed, requires the employment of a non-minimal concept of truth or of something 
which relies on such a conception. There is also a related concern that minimalism cannot both be a complete and consistent theory of truth due to the existence of liar-like propositions and settheoretic paradoxes (cf. Armour-Garb, 'Minimalism, The Generalization Problem and The Liar' 496-7; Lindström, ‘Horwich’s Minimalist Conception of Truth: Some Logical Difficulties’1748; Grim, The Incomplete Universe: Totality, Knowledge and Truth Ch. 4; Greimann, 'Explicating Truth: Minimalism and Primitivism'), a concern I will not pursue here.

In the postscript to Truth, Horwich attempts to subdue instability concerns of this form by emending the minimalist conception of truth, i.e., its conception of the property of truth. According to Horwich, minimalism does not in itself answer the question of whether or not truth is a property, but does so only in conjunction with particular conceptions of property:

Minimalism does not involve, in itself, any particular answer to this question. For it may be combined with a variety of different conceptions of property, some of which will yield the conclusion that the truth predicate does stand for a property, and some that it doesn't. (141)

On first blush, though, this line of reply seems to obscure the instability objection rather than confront it. Horwich's strategy involves exploiting a bipartite, vacillating conception of the property of truth: depending on which view of property is operative, minimalism implies either (a) that truth is a deflated property or (b) that truth is not a property. But it is exactly the bifurcation premise underlying minimalism that seems to give rise to the instability conundrum. The problem evidently is that on (a) minimalism is committed to truth being a deflated property of some kind in which case it is still susceptible to the instability dilemma, and on (b) minimalism is committed to there being no property of truth in which case it collapses into strong deflationism. 
The quandary can be framed in other terms. If the minimalist denies there are facts about truth requiring explanation as such, minimalism effectively devolves into the implausible redundancy theory of truth according to which the truth predicate is redundant and doesn't designate a property. If, on the other hand, the minimalist acknowledges there are facts about truth requiring explanation as such, minimalism effectively evolves into some form of inflationism according to which truth is an inflated property of truth bearers (a property with a genuine explanatory role).

Naturally, this is not the final word on the explanatory merits and/or stability of minimalism. But doubtless minimalism incurs significant, often unacknowledged, commitments concerning the dichotomous nature of concepts (that there is a distinction between trivial-redundant concepts and trivial-non-redundant concepts), predicates (that there is a distinction between predicates that express properties and those that don't) and properties (that there is a distinction between natural/non-natural, explanatory/non-explanatory properties) (cf. O’Leary-Hawthorne and Oppy, 'Minimalism and Truth' 178-9). In the absence of a more robust defense of this implicit ideology, minimalism looks just as unsound as its strong deflationary counterpart. At the very least, there are considerable theoretical obligations the minimalist has yet to discharge.

\section{Works Cited}

Alston William. A Realist Conception of Truth. Ithaca: Cornell University Press, 1996. Armour-Garb, Bradley. 'Minimalism, the Generalization Problem and the Liar'. Synthese 139, (2004): 491-512.

Ayer, A.J. Language, Truth, and Logic. London: Penguin, 1936.

Black, Max. 'The Semantic Definition of Truth'. Analysis 8, (1948): 49-63. 
Boghossian, Paul. 'The Status of Content'. Philosophical Review 99, (1990): 157-84.

Collins, John. 'On the Proposed Exhaustion of Truth'. Dialogue XLI, (2002): 653-79.

David, Marian. Correspondence and Disquotation. New York: Oxford University Press, 1994.

Field, Hatry. 'Deflationist Views of Meaning and Content'. Mind 103, (1994): 249-85.

Grover, Dorothy, Camp, Joseph, and Belnap, Nuel. 'A Prosentential Theory of Truth'. Philosophical Studies 27, (1975): 73-125.

Greiman, Dick. 'Explicating Truth: Minimalism and Primitivism'. Journal for General Philosophy of Science, 31 (2000): 133-55.

Grim, Patrick. The Incomplete Universe: Totality, Knowledge and Truth. Cambridge, Mass.:

MIT Press, 1991.

Gupta, Anil. 'A Critique of Deflationism'. Philosophical Topics 21, (1993): 57-81.

—. 'Minimalism'. Philosophical Perspectives, Language and Logic 7, (1993): 359-69.

Horwich, Paul. Truth. Oxford: Clarendon Press, 1998.

—. Meaning. Oxford: Clarendon Press, 1998.

—. 'A Defense of Minimalism'. Synthese 126, (2001): 149-65.

Kirkham, Robert. Theories of Truth. Cambridge: MIT Press, 1992.

Kovach, Adam. 'Deflationism and the Derivation Game'. Mind 106, (1997): 575-9.

Lindström, Sten. 'Horwich's Minimalist Conception of Truth: Some Logical Difficulties'. Logic and Logical Philosophy 9, (2001): 161-81.

McGrath, Matthew. 'Weak Deflationism'. Mind 106, (1997): 69-98.

O'Leary-Hawthorne, John and Graham, Oppy. 'Minimalism and Truth'. Nous 31.2, (1997): 17096.

Quine, W.V.O. Philosophy of Logic. Englewood Cliffs: Prentice-Hall, 1970.

Ramsey, Frank. 'Facts and Propositions'. Proceedings of the Aristotelian Society 7, (1927): 15370 .

Soames, Scott. 'The Truth About Deflationism'. Philosophical Issues 8, (1997): 1-44.

—.Understanding Truth. New York: Oxford University Press, 1999. 
Sosa, Ernest. 'The Truth of Modest Realism”. Philosophical Issues 3, (1993): 77-95.

Strawson, Peter. 'Truth'. Proceedings of the Aristotelian Society 24, (1950): 129-56.

Williams, C.J.F. What is Truth? Cambridge: Cambridge University Press, 1976.

Wright, Crispin Truth and Objectivity. Cambridge: Harvard University Press, 1992.

- 'Response to Commentators', Philosophy and Phenomenological Research 56, (1996): 863$8,911-41$.

Notes

${ }^{1}$ Unlike the rest of this group, Grover et al. reject the redundancy thesis yet maintain truth does not have a propertyascribing role ('A Prosentential Theory of Truth' 83). Grover et al.'s prosentential theory of truth will not be discussed in this paper.

2 The epistemic theory of truth is considered particularly problematic in this case since it compels the abandonment of classical logic.

${ }^{3}$ Needless to say, unprincipled restriction to the non-paradoxical is notoriously problematic. See Soames (Understanding Deflationism) and Armour-Garb ('Minimalism, the Generalization Problem and the Liar') for an illuminating discussion of this concern.

${ }^{4}$ For precision, generalizations about truth need to be distinguished from generalizations involving truth. Generalizations involving truth are generalizations in which the truth predicate participates, generalizations such as 'Everything claimed by Plato is true' or 'It is true that all red objects are colored objects'. Generalizations about truth, on the other hand, are generalizations that apply to all truth bearers (examples to follow in the text).

${ }^{5}$ Curiously, Soames frames this point in terms of logical equivalence (Understanding Truth 247): “...universal generalizations are not logical consequences of the set of all their instances". Soames' thesis vis-à-vis the logical inequivalence of universal generalizations and the set of all their instances might be correct but, unlike the 'cognitive inequivalence thesis', seems controversial. Moreover, the cognitive inequivalence thesis is sufficient to support our argument in this case. If the cognitive content of universal generalizations and the set of all their instances diverges then minimalism's infinitary schematic definition of truth does not imply or explain universal generalizations about truth such as (C).

${ }^{6}$ I will not rehearse the specific details of the derivation here. Suffice it to say Horwich attempts to produce a valid argument with the principle of entailment and minimalism as its premises and the principle of closure as its conclusion.

${ }^{7}$ Cf. also Meaning for Horwich's dispositional analysis of truth generalizations and other truth-predicated statements.

${ }^{8}$ Field ('Deflationist Views of Meaning and Content' 249-85) offers a similar solution to the generalization problem. 